\title{
Hydrogen Production by Ethanol Steam Reforming
}

\author{
By Adriano Braga* \\ João dos Santos ${ }^{\dagger}$ \\ Jose Maria C. Bueno \\ Sonia Damyanova ${ }^{+}$
}

\begin{abstract}
The structure and surface properties of monometallic (Co or Ni) and bimetallic CoNi catalysts supported on $\mathrm{MgAl}_{2} \mathrm{O}_{4}$ for hydrogen production were studied by applying different techniques for physicochemical characterization such as: $\mathrm{N}_{2} \mathrm{O}$ chemisorption, TPR, XPS and XANES. The test reaction was ethanol steam reforming carried out at a temperature interval of $250{ }^{\circ} \mathrm{C}-750^{\circ} \mathrm{C}$ and a ratio $\mathrm{H}_{2} \mathrm{O} / \mathrm{C}_{2} \mathrm{H}_{5} \mathrm{OH}$ of $3 / 1$. It was shown that the different behavior of catalysts in the $C$ - $C$ breaking depends mainly on the oxidation state of the metal components. It was detected that the acetaldehyde production is large when the oxidation degree of the metal components is at its maximum, i.e. the ethanol oxidative dehydrogenation takes place. Increasing the degree of metallic area in $\mathrm{Ni}$ and CoNi catalysts led to easily $\mathrm{C}-\mathrm{C}$ bond cleavage, producing $\mathrm{CO}, \mathrm{CO}_{2}$ and $\mathrm{H}_{2}$.
\end{abstract}

Keywords: Characterization, CoNi catalysts, Ethanol steam reforming, Hydrogen

\section{Introduction}

Serious environmental problems have been caused by fossil fuels: air pollution and greenhouse gas emissions. The use of renewable alternatives is becoming urgent today. Hydrogen is an ideal energy carrier for sustainable energy development (Mattos et al., 2012), because it is extremely clean since the only by-product at its burning is water. For a sustainable hydrogen economy, it is crucial to produce clean and renewable hydrogen. Nowadays, the reforming processes of natural gas are used for hydrogen production. However, natural gas leads to the formation of large amounts of carbon dioxide emissions during the reforming processes. So, the search for effective alternatives to produce renewable hydrogen is of great interest. Ethanol is a very attractive feedstock because of its relatively high hydrogen content, availability, non-toxicity and storage. Ethanol can be produced by the fermentation of biomass sources, such as energy plants, agro-industrial wastes, forestry residue materials, and organic fraction of municipal solid waste. The

\footnotetext{
${ }^{*}$ PhD Student, Federal University of Sao Carlos, Brazil.

${ }^{\dagger}$ Associate Professor, Department of Chemical Engineering, Federal University of Sao Carlos, Brazil.

${ }^{\ddagger}$ Professor, Department of Chemical Engineering, Federal University of Sao Carlos, Brazil.

${ }^{+}$Professor, Institute of Catalysis, Bulgarian Academy of Sciences, Bulgaria.
} 
ethanol produced this way is called "bioethanol". Ethanol steam reforming (ESR) is a promising method for hydrogen production from renewable resources.

The control of carbon deposition on the metal surface, which is fundamental to obtain stable and active catalysts, is one of the main challenges for ESR. The use of suitable catalysts plays a crucial role in hydrogen production from ESR, since each catalyst induces different pathways in ethanol reforming (Zanchet et al., 2015). The active catalysts should maximize the hydrogen selectivity and inhibit coke formation as well as $\mathrm{CO}$ production. It is well known that noble metal catalysts exhibit high catalytic activity in ESR (Cavallaro et al., 2003; Fierro et al., 2003). However, due to the high cost of noble metals the most commonly used catalysts in reforming processes for hydrogen production are $\mathrm{Ni}$-based catalysts because of their low cost and wide availability. In addition, the choice of $\mathrm{Ni}$ is the best one for hydrogen production by ESR since Ni has a high activity for the breaking of $\mathrm{C}-\mathrm{C}$ and $\mathrm{O}$ $\mathrm{H}$ bonds and a high activity in hydrogenation, in this way facilitating the hydrogen atoms to form molecular $\mathrm{H}_{2}$ (Zanchet et al., 2015).

On the other hand, the selection of suitable support for catalysts and the methods of catalyst preparation significantly affect catalyst activity. The most used support is $\gamma-\mathrm{Al}_{2} \mathrm{O}_{3}$ due to its high specific surface area and high thermal stability. But, alumina-supported $\mathrm{Ni}$ or noble metal catalysts deactivate very fast in ESR due to the acidic character of the support that favors the ethanol dehydration to ethylene, which is a source for carbon formation. In terms of hydrogen production and long-term catalyst stability it was shown that the addition of metal with basic nature to alumina can favor the ethanol reforming to hydrogen and suppress the carbon species formation. The development of bimetallic catalysts or alloy catalysts is also promising to enhance the hydrogen production and long-term stability of Ni-based catalysts. It was shown (Batista et. al., 2004) that Co catalysts studied in ESR reaction revealed a lower hydrogenation activity of $\mathrm{CH}_{\mathrm{x}}$ radicals at low reaction temperatures compared to that of $\mathrm{Ni}$ one due to the electronic properties of Co. In addition, Co has better ability to oxidize carbon deposits, which are accumulated during ethanol reforming. The modification of $\mathrm{Ni}$ catalysts by the addition of Co can lead to the increase of metal dispersion, degree of reduction and/or to favor the proceeding of ethanol reforming to hydrogen at lower reaction temperatures and to suppress the carbon accumulation.

In the present work it is attempted to develop bimetallic CoNi catalysts supported on a basic support like $\mathrm{MgAl}_{2} \mathrm{O}_{4}$ for hydrogen production by ethanol steam reforming. Different techniques have been used for physicochemical characterization of the samples such as: $\mathrm{N}_{2} \mathrm{O}$ chemisorption, X-ray photoelectron spectroscopy (XPS), temperature programmed reduction (TPR) and X-ray absorption near edge structure (XANES). The test reaction was ethanol steam reforming at different reaction temperatures. 


\section{Experimental}

\section{Sample Preparation}

$\mathrm{MgAl}_{2} \mathrm{O}_{4}$-supported $\mathrm{CoNi}$ catalysts were prepared by incipient wetness coimpregnation of $\mathrm{MgAl}_{2} \mathrm{O}_{4}$ with aqueous solutions of $\mathrm{Ni}\left(\mathrm{NO}_{3}\right)_{2} \cdot 6 \mathrm{H}_{2} \mathrm{O}$ (Aldrich, $99 \%$ ) and $\mathrm{Co}\left(\mathrm{NO}_{3}\right)_{2} \cdot 6 \mathrm{H}_{2} \mathrm{O}$ (Aldrich, $99 \%$ ) at $343 \mathrm{~K}$. The samples were dried at $110^{\circ} \mathrm{C}$ and calcined at $550^{\circ} \mathrm{C}$ under synthetic air for 12 and $6 \mathrm{~h}$, respectively. The $\mathrm{MgAl}_{2} \mathrm{O}_{4}$ support was prepared by a sol-gel method described by (AvilaNeto et al., 2012). The samples were designated as $8 \mathrm{Co}, 8 \mathrm{Ni}$ and $4 \mathrm{Co} 4 \mathrm{Ni}$, where the number represents the metal loading in wt.\%.

\section{Sample Characterization}

$\underline{\mathrm{XPS}}$

The XP spectra of the samples previously reduced in the chamber at $750^{\circ} \mathrm{C}$ in a flow of $10 \% \mathrm{H}_{2} / \mathrm{He}$ for $2 \mathrm{~h}$ was recorded with a SPECSLAB II PHOIBOSHSA 3500150 spectrometer containing nine detection channels and a hemispherical analyzer, employing $\mathrm{Al} \mathrm{K} a$ radiation $(1486.6 \mathrm{eV})$. The analyzer was operated in a constant pass energy mode $\left(\mathrm{E}_{\text {pass }}=40 \mathrm{eV}\right)$. Binding energies (BE) were referenced to Al 1s core level of $\gamma$-alumina $(121 \mathrm{eV})$. The vacuum level during the experiments was below $10^{-7} \mathrm{~Pa}$.

\section{$\underline{\text { XANES }}$}

Temperature resolved X-ray absorption near edge spectroscopy analysis in situ under $\mathrm{H}_{2}$ atmosphere $\left(\mathrm{H}_{2}\right.$-XANES) was performed at Co $\mathrm{K}$ edge $(7709 \mathrm{eV})$ and $\mathrm{Ni} \mathrm{K}$ edge $(8333 \mathrm{eV})$ in a $5 \% \mathrm{H}_{2} / \mathrm{He}$ flow, heating from room temperature up to $750^{\circ} \mathrm{C} \mathrm{K}$ at $10^{\circ} \mathrm{C} \mathrm{min}^{-1}$, since the last temperature was kept for $1 \mathrm{~h}$. D06A-DXAS beam line at the Brazilian Synchrotron Light Laboratory was used. The samples were prepared as self-supporting pellets containing $60 \mathrm{mg}$ of catalysts and placed into a tubular quartz furnace sealed with kapton refrigerated windows for the transmission measurements. A linear combination fitting method was used to obtain information about the oxidation state and the proportion of $\mathrm{CoO}, \mathrm{Co}_{2} \mathrm{O}_{3}, \mathrm{NiO}$ and of $\mathrm{Co}$ and $\mathrm{Ni}$ metal evolution in the TPR experiments of the samples.

\section{$\underline{\text { TPR }}$}

The TPR profiles of the fresh samples were recorded on a Micromeritics AutoChem II 2920 with a thermo-conductivity detector. The sample $(0.150 \mathrm{~g})$ loaded in a quartz reactor was pretreated at $200^{\circ} \mathrm{C}$ in a He stream for $1 \mathrm{~h}$ in order to remove surface contaminants. After cooling to r.t. a flow of $10 \%$ $\mathrm{H}_{2} / \mathrm{N}_{2}(30 \mathrm{ml} / \mathrm{min})$ was passed through the reactor and the temperature was raised up to $1000^{\circ} \mathrm{C}$ at a rate of $10^{\circ} \mathrm{C} / \mathrm{min}$ while the TCD signal was recorded.

$\mathrm{N}_{2} \mathrm{O}$ titration was used to determine the area and dispersion of metallic particles. The samples were loaded in the same TPR apparatus, where they were previously reduced up to $750^{\circ} \mathrm{C}$ in a $10 \% \mathrm{H}_{2} / \mathrm{N}_{2}$ flow for $1 \mathrm{~h}$ and after that were cooled to $60^{\circ} \mathrm{C}$ in a $\mathrm{N}_{2}$ flow and exposed to $\mathrm{N}_{2} \mathrm{O}$ impulses $(1 \mathrm{ml})$ for 5 min. The metallic area was calculated according to the Ref. (Sato et al., 2013). 


\section{Test Reaction}

The steam of the reforming of $\mathrm{C}_{2} \mathrm{H}_{5} \mathrm{OH}$ was carried out in a vertical fixedbed reactor made from a quartz tube under atmospheric pressure and at a temperature interval of $250^{\circ}-700^{\circ} \mathrm{C}$ with a molar ratio of $\mathrm{H}_{2} \mathrm{O} / \mathrm{C}_{2} \mathrm{H}_{5} \mathrm{OH}=3 / 1$. The catalyst sample was $120 \mathrm{mg}$. Before the reaction test, the catalyst was reduced in situ by heating it in a $10 \% \mathrm{H}_{2} / \mathrm{N}_{2}$ flow at $750^{\circ} \mathrm{C} \mathrm{K}$ at a rate of $10^{\circ}$ $\min ^{-1}$ and maintaining the temperature for $1 \mathrm{~h}$. The reaction products were analyzed by gas chromatograph (VARIAN 3400CX) with a Chromosorb 102 packed column, while hydrogen was detected by mass spectrometry (Pfeiffer PrismaPlus).

\section{Results and Discussion}

\section{Physicochemical Properties}

Comparing the values of the average metallic area, dispersion and the particle size of $\mathrm{Co}$ and $\mathrm{Ni}$ of the reduced samples (at $750^{\circ} \mathrm{C}$ ) obtained by $\mathrm{N}_{2} \mathrm{O}$ chemisorption (Table 1) it can be seen that the highest values are obtained from the monometallic Ni catalyst in contrast to that observed for Co. This means that the $\mathrm{MgAl}_{2} \mathrm{O}_{4}$-supported $\mathrm{Ni}$ catalyst is well reduced. The addition of Co to the Ni catalyst leads to a decrease of the metallic area, as well as the size of the metallic particles. This could be related to the presence of a high concentration of oxide species in the bimetallic $\mathrm{CoNi}$ system under its treatment in a hydrogen atmosphere caused by some interaction between $\mathrm{Ni}$ and $\mathrm{Co}$.

The intimate contact between $\mathrm{Co}$ and $\mathrm{Ni}$ is also supported by the results of the XPS analysis of reduced monometallic and bimetallic catalysts. The values of the BEs of $\mathrm{Ni} 2 \mathrm{p}_{3 / 2}$ and Co $2 \mathrm{p}_{3 / 2}$ core electrons and the atomic XPS ratios of reduced samples are listed in Table 1 . The BEs of $\mathrm{Ni} 2 \mathrm{p}_{3 / 2}(855.48-855.98 \mathrm{eV})$ and $\mathrm{Co} 2 \mathrm{p}_{3 / 2}$ signals (780.83-781.05 eV) for oxide samples characterized $\mathrm{Ni}^{2+}$ and $\mathrm{Co}^{2+}$ ions, respectively. It should be noted that these values are higher compared to those characteristics of bulk $\mathrm{NiO}(854.5 \mathrm{eV})$ and $\mathrm{Co}_{3} \mathrm{O}_{4}(779 \mathrm{eV})$ (Andonova et al., 2011). This one could be connected with the strong interaction of nickel and cobalt oxide species with the support surface as well as with the interaction between $\mathrm{Ni}$ and $\mathrm{Co}$ in the case of the bimetallic $\mathrm{CoNi}$ sample. Some displacement in the BEs is observed for reduced samples (Table 1). For the bimetallic CoNi system the $\mathrm{BE}$ of $\mathrm{Ni} 2 \mathrm{p}_{3 / 2}(852.84 \mathrm{eV})$ is higher compared to that of monometallic $8 \mathrm{Ni}(852.52 \mathrm{eV})$. At the same time, the $\mathrm{BE}$ value of Co $2 p_{3 / 2}$ for the bimetallic CoNi system $(778.47 \mathrm{eV})$ is significantly lower relative to that of monometallic $8 \mathrm{Co}(781.76 \mathrm{eV})$. It means that the deficiency of electrons in the environment of $\mathrm{Ni}$ in opposite to that observed for $\mathrm{Co}$, which is most probably caused by the interaction between $\mathrm{Co}$ and $\mathrm{Ni}$ and alloy formation. The same phenomenon was observed by (Zhang et al., 2009). 
Table 1. Characteristics from $\mathrm{N}_{2} \mathrm{O}$ Chemisorption, BE Values of $\mathrm{Ni} 2 p$ and Co2p Signals for $\mathrm{Co}, \mathrm{Ni}$ and CoNi Samples

\begin{tabular}{|c|c|c|c|c|c|}
\hline Sample & $\begin{array}{c}\text { Dispersion } \\
(\mathbf{\%})\end{array}$ & $\begin{array}{c}\text { Metal area } \\
(\mathbf{\%})\end{array}$ & $\begin{array}{c}\text { Particle size } \\
(\mathbf{n m})\end{array}$ & $\begin{array}{c}\mathbf{N i} \mathbf{2 p}_{\mathbf{3} / \mathbf{2}} \\
(\mathbf{e V})\end{array}$ & $\begin{array}{c}\mathbf{C o} \mathbf{2 p}_{\mathbf{3} / \mathbf{2}} \\
(\mathbf{e V})\end{array}$ \\
\hline $8 \mathrm{Ni}$ & 16.6 & 8.83 & 6.1 & 852.5 & - \\
\hline $4 \mathrm{Co} 4 \mathrm{Ni}$ & 13.6 & 7.29 & 7.4 & 852.8 & 778.5 \\
\hline $8 \mathrm{Co}$ & 1.4 & 0.79 & - & - & 781.8 \\
\hline
\end{tabular}

Also it should be noted the fact that the XPS spectra of the reduced monometallic Co sample exhibited a major concentration of $\mathrm{Co}^{2+}$ species in comparison to that of $\mathrm{Co}^{0}$. This could be caused by the higher dispersion of the small cobalt particles in a strong interaction with support. The higher atomic XPS Ni/Co ratio for the reduced bimetallic sample (2.8) in relation to that of the calcined sample (1.6) means a segregation of $\mathrm{Ni}$ on the Co particles and the formation of a structure similar to core-shell type.

Additional insight regarding the influence of $\mathrm{Co}$ addition to $\mathrm{MgAl}_{2} \mathrm{O}_{4}$ supported $\mathrm{Ni}$ on the metal oxidation state was investigated by in situ temperature-resolved XANES spectroscopy at K-edge of Ni and Co during sample reduction in a hydrogen atmosphere up to $750^{\circ} \mathrm{C}$. The change of percentage of nickel and cobalt species in monometallic and bimetallic CoNi systems is shown in Figure 1. It can be seen that at low reduction temperature there is no significant alteration in the percentage of $\mathrm{Ni}$ species for the $8 \mathrm{Ni}$ sample. More visible change is observed above $300^{\circ} \mathrm{C}$ : the percentage of $\mathrm{NiO}$ species decreases with increasing the reduction temperature, while that of the metallic Ni component increases. The Ni oxide species on the surface of the bimetallic $\mathrm{CoNi}$ system are characterized by a higher reduction temperature compared to that of the Ni sample (above $400^{\circ} \mathrm{C}$ ). The latter suggests that the presence of $\mathrm{Co}$ suppresses the reduction of $\mathrm{Ni}$ at lower temperatures. In addition, the latter stage of TPR experiments at a higher reduction temperature $\left(\right.$ at $750^{\circ} \mathrm{C}$ ) shows a higher fraction of reduced $\mathrm{Ni}$ species for $\mathrm{CoNi}$ in relation to that of $8 \mathrm{Ni}$.

Despite the observed similarity in the percentage change of the Co species for the Co and CoNi samples there is an important difference for both samples related to the reducibility and the reduction temperatures of the transformation of the Co oxide species to metallic cobalt (Figure 1). For the monometallic 8Co sample the percentage change of the Co species under hydrogen treatment clearly demonstrates the two step reduction process of the $\mathrm{Co}_{3} \mathrm{O}_{4}$ species to metallic $\mathrm{Co}^{0}$ passing through the formation of $\mathrm{CoO}$ as an intermediate: $\mathrm{Co} 3 \mathrm{O} 4$ $+\mathrm{H} 2=3 \mathrm{CoO}+\mathrm{H} 2 \mathrm{O}$ and $3 \mathrm{CoO}+3 \mathrm{H} 2=3 \mathrm{Co}+3 \mathrm{H} 2 \mathrm{O}$ (Ji et al., 2009). The reduction temperature of the first step transformation of $\mathrm{Co}_{3} \mathrm{O}_{4}$ to $\mathrm{CoO}$ was significantly lower for the monometallic Co sample and finished at about $500^{\circ} \mathrm{C}$. Above that temperature the formation of $\mathrm{Co}^{0}$ is due to the reduction of $\mathrm{CoO}$ to $\mathrm{Co}^{0}$ (second step). In the case of the CoNi sample the presence of $\mathrm{Co}_{3} \mathrm{O}_{4}$ is observed up to a higher reduction temperature of $750^{\circ} \mathrm{C}$, which is 
accompanied with a high fraction of metallic Co and with a decreased amount of $\mathrm{CoO}$.

In addition, the fraction of metallic Co for this sample is high at a lower reduction temperature interval $\left(300^{\circ}-500^{\circ} \mathrm{C}\right)$ as well as at the end of the reduction process. It can be concluded that an easier reduction of the Co species to $\mathrm{Co}^{0}$ is observed for the bimetallic system. The direct transformation of the $\mathrm{Co}_{3} \mathrm{O}_{4}$ species to $\mathrm{Co}^{0}$ for $\mathrm{CoNi}$ is prevalent at higher temperature. It is important to note that fractions of metallic $\mathrm{Co}$ and $\mathrm{Ni}$, as well as fractions of $\mathrm{Co}$ and $\mathrm{Ni}$ oxide species are observed for all samples at the end of the reduction process at $750^{\circ} \mathrm{C}$. The reducibility of $\mathrm{Co}$ and $\mathrm{Ni}$ for the bimetallic system is improved, being confirmed by the higher fraction of metallic species at the end of reduction.

Figure 1. Percentage Change of the Ni and Co Species of the Samples during in situ XANES- $\mathrm{H}_{2}$ at $\mathrm{K}$-edge of $\mathrm{Ni}$ and $\mathrm{Co}$

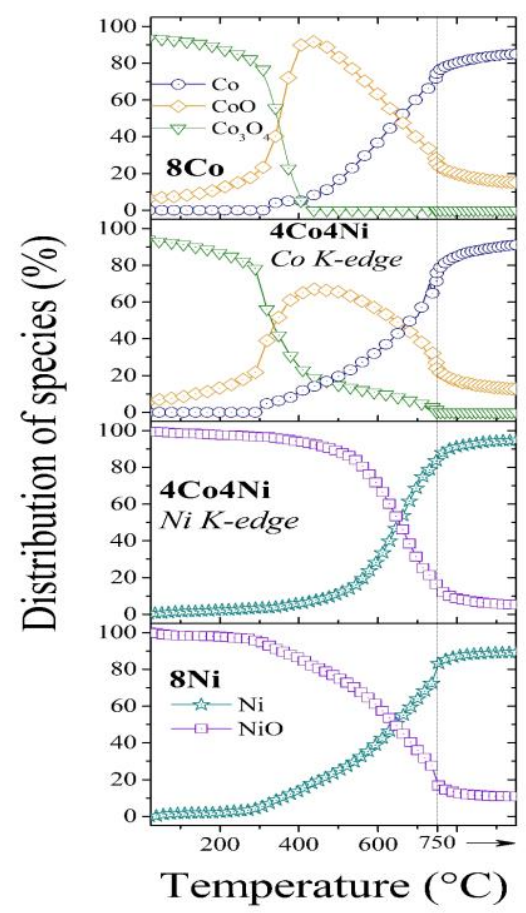

Information about the reduction of the $\mathrm{Co}$ and $\mathrm{Ni}$ oxide species on the surface of $\mathrm{MgAl}_{2} \mathrm{O}_{4}$ support in monometallic and bimetallic systems was also obtained by the TPR. Figure 2 shows the TPR profiles of $\mathrm{Co}, \mathrm{Ni}$ and $\mathrm{CoNi}$ samples. The TPR profile of $8 \mathrm{Ni}$ exhibits a low temperature feature at $378^{\circ} \mathrm{C}$ as well as a strong asymmetric TPR signal with a maximum at about $665^{\circ} \mathrm{C}$ due to the reduction of bulk $\mathrm{NiO}$ clusters weakly bound to the $\mathrm{MgAl}_{2} \mathrm{O}_{4}$ surface and to the reduction of small $\mathrm{NiO}$ crystals in a strong interaction with support, respectively. It suggests a presence of $\mathrm{Ni}$ oxide species with a different morphology on the surface of $\mathrm{MgAl}_{2} \mathrm{O}_{4}$. 
The TPR profile of $8 \mathrm{Co}$ can be divided into two major features. The first peak at $376^{\circ} \mathrm{C}$ with a shoulder at $321^{\circ} \mathrm{C}$ can be assigned to a two-step reduction process of $\mathrm{Co}_{3} \mathrm{O}_{4}$ to metallic $\mathrm{Co}^{0}$ passing through the formation of $\mathrm{CoO}$ as an intermediate that is similar to the XANES results. The hydrogen consumption in the higher temperature region could be caused by the reduction of small well dispersed Co oxide species in a strong interaction with support.

The addition of Co to Ni sample leads to a visible change in the reduction profile of the bimetallic 4Co4Ni system. The initial stage of reduction of the oxide species of the CoNi sample is shifted to lower temperatures than that of monometallic $\mathrm{Ni}$ and Co samples (Figure 2). According to the results in the literature (Zhang et al., 2008), the formation of Ni-Co-alloy during the reduction can occur. The latter facilitates the reduction process to proceed at a lower temperature. At the same time the maximum TPR peak of the $\mathrm{CoNi}$ sample at a higher temperature range is shifted to a higher value indicating a stronger interaction of the well dispersed $\mathrm{Co}$ and $\mathrm{Ni}$ species with support.

Figure 2. TPR Profiles of Monometallic and Bimetallic CoNi Catalysts

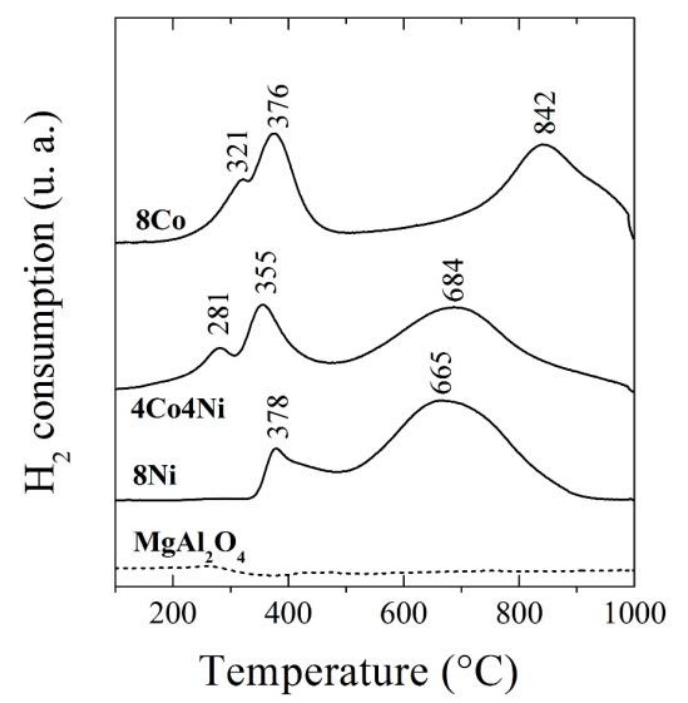

\section{Catalyst Behaviors in ESR}

Figure 3 shows the ethanol conversion and the distribution of products as a function of a reaction temperature in the range of $250^{\circ}-700^{\circ} \mathrm{C}$. From the Figure 3 it can be seen that the ethanol conversion for all samples increases with increasing the reaction temperature and the maximum conversion of ethanol to $\mathrm{CO}_{2}, \mathrm{CO}$ and $\mathrm{H}_{2}$ is achieved at $600^{\circ}, 450^{\circ}$ and $550^{\circ} \mathrm{C}$ for $8 \mathrm{Ni}, 4 \mathrm{Co} 4 \mathrm{Ni}$ and $8 \mathrm{Co}$ samples, respectively. It should be noted that the reaction pathways in ethanol steam reforming at lower temperatures is strongly dependent on the capacity of the active metals to break the $\mathrm{C}-\mathrm{C}$ bond in $\mathrm{C}_{2} \mathrm{H}_{5} \mathrm{OH}$ molecule (Zanchet et al., 2015). The results for the $\mathrm{Ni}$ catalyst show that at $300^{\circ} \mathrm{C}$, ethanol is first dehydrogenated with desorption of $\mathrm{CH}_{3} \mathrm{CHO}$ and $\mathrm{H}_{2}$. In parallel to a hydrogen abstraction from the ethanol molecule, the $\mathrm{C}-\mathrm{C}$ bond scission and the 
decomposition of acetaldehyde is also observed with increasing the temperature up to $350^{\circ} \mathrm{C}$. This results in the formation of $\mathrm{CH}_{4}, \mathrm{CO}$ and $\mathrm{H}_{2}$ with a $\mathrm{CO} / \mathrm{CH}_{4}$ ratio of about one. Over the monometallic Co catalyst the relative abundant acetaldehyde at $300^{\circ} \mathrm{C}$ indicates that $\mathrm{Co}$ has weaker capability of breaking the $\mathrm{C}-\mathrm{C}$ bond in an ethanol molecule. Above this temperature products due to $\mathrm{C}-\mathrm{C}$ scission begin to be observed. A low $\mathrm{CO} / \mathrm{CO}_{2}$ ratio up to $500^{\circ} \mathrm{C}$ is detected for Co catalyst that can be related to the presence of $\mathrm{Co}$ oxide species decreasing the ability of $\mathrm{C}-\mathrm{C}$ breakage. The catalytic behavior of the CoNi catalyst at lower reaction temperatures is between those of the both monometallic catalysts (Figure 3). At lower temperatures acetaldehyde is mainly formed on the surface of the bimetallic system, but in an amount much lower compared to that observed for the Co catalyst indicating a better reducibility of the bimetallic catalyst.

Figure 3. Evaluation of Ethanol Conversion and Chemicals Products as a Function of Reaction Temperature

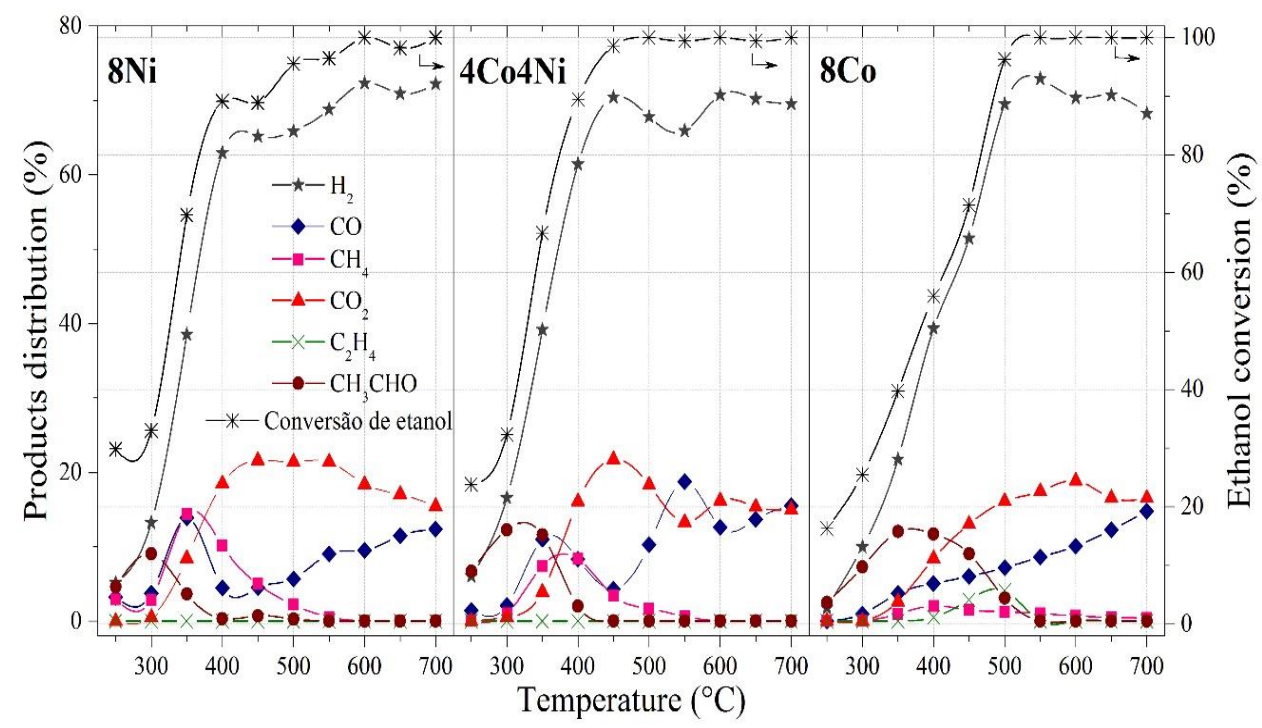

Above $300^{\circ} \mathrm{C}$ the behavior of $\mathrm{CoNi}$ is similar to that of $\mathrm{Ni}$ in spite of the lower amount of $\mathrm{CH}_{4}$. Above $400^{\circ} \mathrm{C}$ the amount of $\mathrm{CO}_{2}$ increases for all catalysts due to the activation of water and of the water-gas shift reaction (WGSR) that leads to hydrogen production. However, over the Co surface in spite of the formation of $\mathrm{CO}, \mathrm{CO}_{2}$ and $\mathrm{H}_{2}$ in low concentration, a high amount of desorbed $\mathrm{CH}_{3} \mathrm{CHO}$ is still present due to the high concentration of oxide species. Above $550^{\circ} \mathrm{C}$ an inversion in the $\mathrm{CO}_{2} / \mathrm{CO}$ ratio was observed for all catalysts, most probably caused by the reverse of WGSR. 


\section{Conclusions}

Using $\mathrm{MgAl}_{2} \mathrm{O}_{4}$ as a support for the monometallic $\mathrm{Co}$ and $\mathrm{Ni}$ as well as for the bimetallic $\mathrm{CoNi}$ catalyst can guarantee a high thermal stability of the catalysts. Addition of Co to the Ni catalyst leads to: (i) alloy formation, which changes the electronic properties of the bimetallic catalyst and (ii) improves the redox properties.

According to the thermodynamic calculations by (van Steen et al., 2005) Co particles less than $4 \mathrm{~nm}$ are unstable and can be easily oxidized in the presence of steam due to the increased free energy on the surface. This is in accordance with the loss of the activity of the 8Co catalyst under the ESR process due to the decrease of the number of active centers (Figure 3). In the case of the bimetallic CoNi catalyst the oxidation state of Co is stabilized to $\mathrm{Co}^{0}$ due the presence of alloy and the redox properties of catalyst are improved.

It is important to note that the formation of $\mathrm{CH}_{4}$ is a very important point for the ESR mechanism. The $8 \mathrm{Ni}$ catalyst demonstrates the highest activity to hydrogenation of $\mathrm{CH}_{\mathrm{x}}$ radical caused by the $\mathrm{C}-\mathrm{C}$ cleavage. The monometallic $8 \mathrm{Co}$ catalyst leads to less methane formation due to the lower number of the active metallic centers. According to (Watwe et al., 2000) the free energy for hydrogenation of the $\mathrm{CH}_{\mathrm{x}}$ species is low over the Ni surface that support our conclusions. Increasing the reaction temperature leads to the formation of products from the ethanol decomposition: $\mathrm{H}_{2}, \mathrm{CO}$ and $\mathrm{CO}_{2}$. It is important to note that for the bimetallic catalyst the selectivity to $\mathrm{H}_{2}$ production is higher as well as less carbon is formed. This means that the electronic properties of the 4Co4Ni catalyst are more evident that leads to a more selective and stable catalyst.

\section{Acknowledgments}

Our thanks to FAPESP and FNI (project E02/16) for financial support.

\section{References}

Andonova, S., de Avila, C. N., Arishtirova, K., Bueno, J. M. C., Damyanova S. (2011). Structure and redox properties of Co-promoted $\mathrm{Ni} / \mathrm{Al}_{2} \mathrm{O}_{3}$ catalyst for oxidative steam reforming of ethanol. Appl. Catal. B: Environ. 15, 346-360.

Avila-Neto, C. N., Liberatori, J. W. C., da Silva, A. M., Zanchet, D. C., Hori, E., Noronha, F.B., Bueno, J.M.C. (2012). Understanding the stability of Cosupported catalysts during ethanol reforming as addressed by in situ temperature and spatial resolved XAFS analysis. J. Catal. 287, 124-137.

Batista, M. S., Santos, R. K. S., Assaf, E. M., Assaf, J. M., Ticianelli, E. A. (2004). High efficiency steam reforming of ethanol by cobalt-based catalysts. J. Power Sources 134, 27-32. 
Cavallaro, S., Chiodo, V., Freni, S., Mondello N., Frusteri, F. (2003). Performance of $\mathrm{Rh} / \mathrm{Al}_{2} \mathrm{O}_{3}$ catalyst in the steam reforming of ethanol: $\mathrm{H}_{2}$ production for MCFC. Appl. Catal. A: Gen. 249, 119-128.

Fierro, V., Akdim O., Mirodatos, C. (2003). On-board hydrogen production in a hybrid electric vehicle by bio-ethanol oxidative steam reforming over $\mathrm{Ni}$ and noble metal based catalysts. Green Chemistry 5, 20-24.

Ji Y., Zhao, Z., Duan, A., Jiang, J., Liu, J. (2009). Comparative Study on the Formation and Reduction of Bulk and $\mathrm{Al}_{2} \mathrm{O}_{3}$-Supported Cobalt Oxides by $\mathrm{H}_{2-}$ TPR Technique. J. Phys. Chem. C 113, 7186-7199.

Mattos, L.V., Jacobs G., Davis, B.H., Noronha, F.B. (2012). Production of Hydrogen from Ethanol: Review of Reaction Mechanism and Catalyst Deactivation. Chem. Reviews 112, 4094-4123.

Sato, A. G., Volanti, D. P., Meira, D. M., Damyanova, S., Longo, E., Bueno, J. M. C. (2013). Effect of the $\mathrm{ZrO}_{2}$ phase on the structure and behavior of supported $\mathrm{Cu}$ catalysts for ethanol conversion. J. Catal. 307, 1-17.

van Steen, E., Claeys, M., Dry, M. E., van de Loosdrecht, J., Viljoen, E. L., Visagie, J. L. (2005). Stability of nanocrystals: thermodynamic analysis of oxidation and rereduction of cobalt in water/hydrogen mixtures. J. Phys. Chem. B 109, 35753577.

Watwe, R., Bengard, H, Rostrup-Nelsen, J., Dumestic, J., Norskov. J. (2000). Theoretical Studies of Stability and Reactivity of $\mathrm{CH}_{x}$ Species on $\mathrm{Ni}(111) . J$. Catal. 18, 16-30.

Zanchet, D., Santos, J. B., Damyanova, S., Gallo J. M., Bueno, J. M. (2015). Toward Understanding Metal-Catalyzed Ethanol Reforming. ACS Catal. 5, 3841-3863.

Zhang, J., Wang, H., Dalai, A.K. (2008). Effects of metal content on activity and stability of Ni-Co bimetallic catalysts for $\mathrm{CO}_{2}$ reforming of CH4. Appl. Catal. A: Gen. 339, 121-129.

Zhang, J., H., Wang, A. K., Dalai, K.A. (2009). Kinetic Studies of Carbon Dioxide Reforming of Methane over Ni-Co/Al-Mg-O Bimetallic Catalyst. Ind. \& Eng. Chem. Res. 48, 677-684. 